\title{
Successful Treatment of Condyloma Acuminata Using Office-Made Topical 60\% Betel Leaf Extract
}

\author{
Reinecia Hidayat*, Idrianti Idrus, Muhlis Yunus, Safruddin Amin, Anni Adriani, Muji Iswanty \\ Department of Dermatology and Venereology, Faculty of Medicine, Hasanuddin University, Makassar, Indonesia
}

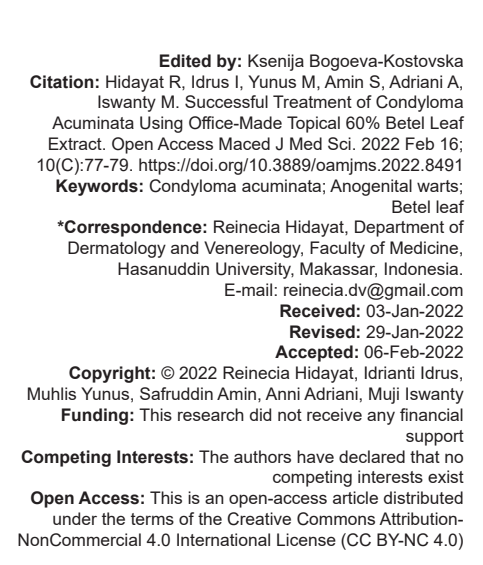

Abstract

BACKGROUND: Condyloma acuminata (CA), also known as anogenital warts, is a predominantly sexually transmitted disease caused by the Human Papillomavirus (HPV). The most common strains of HPV that causes anogenital warts are Type 6 and 11. This vdisease affects the mucous membrane as well as skin of the external genitalia and perianal areas. There are several therapeutic modalities for CA such as destructive and surgical therapies; however, these therapies can pose side-effects mostly tissue destruction. Alternative modalities such as using betel leaf can be atreatment option for CA

CASE REPORT: In this paper, we report a 31-year-old female with CA who experienced clinical improvement after 3 weeks of office-made $60 \%$ topical betel leaf extract therapy, prompting more thorough research on the possible use of herbal treatments for treating CA.

CONCLUSION: Office-made betel leaf extract therapy is a promising topical therapy for CA and is relatively simple to prepare. The plant has various mechanisms such as anti-proliferative and cytotoxic properties that can be studied further to prove its efficacy in the treatment of CA to prevent adverse events caused by other conventional destructive treatment modalities.

\section{Introduction}

Condyloma acuminata (CA) is a benign proliferative lesion caused by the human papillomavirus (HPV). In 2008, 39.9 million women in the United States were infected with HPV. Certain subtypes, such as 6 and 11, are associated with CA, whereas others, such as 16 or 18 , are susceptible to malignant transformation. CA $90 \%$ is caused by non-oncogenic HPV Types 6 or 11 [1], [2], [3].

$\mathrm{CA}$ is generally found on the mucous membranes and skin of the external genitalia or in the perianal area. The lesions are generally cauliflower-like in shape. On the mucosal surface, the lesions often macerate and appear pale, but on glabrous skin, the lesions become more hyperkeratotic. CA can be asymptomatic but there may also be symptomatic in the form of itching, discomfort, and at times dyspareunia [4]. HPV is most commonly transmitted through sexual intercourse. However, transmission of virus through other routes such as direct contact or indirect contact through contaminated items although rare can also occur. The disease is mostly benign and has a low oncogenic potential [4], [5], [6].
At present, the treatment of $\mathrm{CA}$ is more focused on removing the proliferative tissue, rather than eradicating the virus. Some of the modalities of therapy include topical therapy, physical or destructive removal of the lesion with cryotherapy, electrocautery, laser, photodynamic therapy, or surgical excision. However, some of these therapeutic modalities can cause significant adverse events such as pain, itching, burning, and irritation [4], [6]. The use of herbal therapies such as betel leaves can be a safer alternative that produces less adverse events compared to conventional treatments.

We report a case of a 31-year-old woman with CA who experienced clinical improvement after 3 weeks of topical application of office-made $60 \%$ betel leaf extract. As the use of betel leaf extract as therapy for HPV infections is still limited, we chose the $60 \%$ concentration based on the study of its antibacterial properties by Hamka et al. where they evaluated the efficacy of betel extract in $15 \%, 30 \%$, and $60 \%$, respectively. They found that the $60 \%$ has the highest result of antibacterial properties using the disc method [7]. It is hoped that this case report can provide a new perspective on alternative therapy for $\mathrm{CA}$, although further studies on the effects of betel leaf extract on CA are needed. 


\section{Case Report}

A 31-year-old woman visited the Dermatology and Venereology Clinic of Hasanuddin University Hospital with the chief complaint of several genital warts that coalesced on both sides of the labia minora 1 month before. Initially, the lesion started as one small wart which rapidly proliferate and spread across the labia minora. The patient did not experience any itching, pain, or bleeding. The patient is married and her spouse did not experience similar complaints and claimed to be in a monogamous relationship. The lesions had yet to be treated.

Dermatological examination found multiple verrucous papules on the labia minora (Figure 1). The patient was diagnosed with CA and was treated with topical betel leaf extract which was applied 3 times daily. The topical preparation was office made, where $30 \mathrm{~g}$ of betel leave extract was dried, crushed into powder, and mixed in $50 \mathrm{cc}$ of $96 \%$ alcohol for $24 \mathrm{~h}$ (Figure 2a-c). The substance was then boiled for $4 \mathrm{~h}$ and mixed with $50 \mathrm{~g}$ of Vaseline. The patient was instructed to apply the ointment twice daily and was also educated not to have sexual intercourse (abstinence) during treatment and maintain the hygiene. The patient did not apply additional topical or systemic treatments for her complaint and was asked to report any adverse events encountered during treatment.

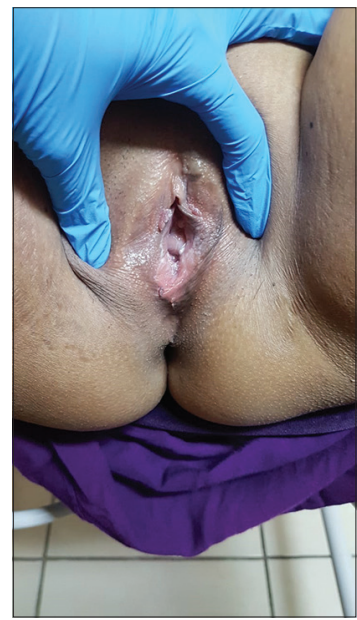

Figure 1: Verrucous papules on the labia minora

After 2 weeks of treatment, we found significant improvement with reduction in size of the verrucous papules (Figure 3a). The patient did not experience

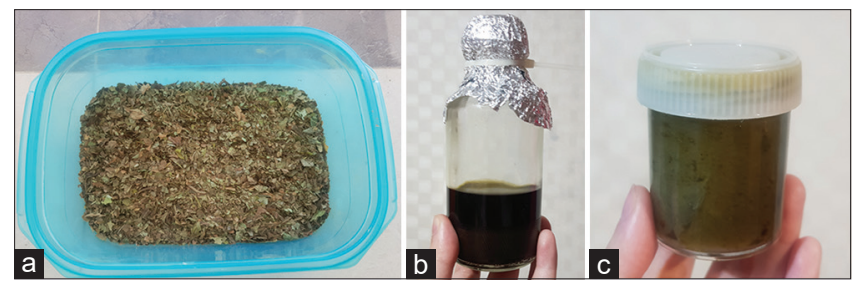

Figure 2: Crushed Betel Leaves (a); Mixed with 96\% Alcohol (b); and Vaseline (c)

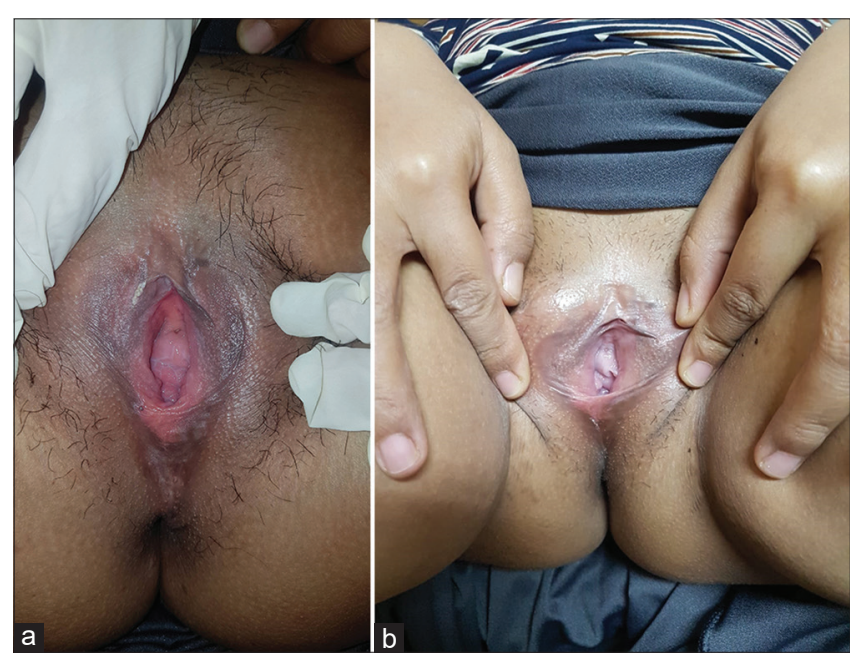

Figure 3: Improvement of CA with reduction in size of verrucous papules (a) and complete resolutin of lesions after 2 weeks of therapy (b)

any adverse events during treatment. We then opted to increase the number of applications to 3 times daily as well as application of the topical extract after urination. After a total of 4 weeks of application, there was complete resolution of the lesions (Figure $3 b$ ).

\section{Discussion}

The incidence of HPV infection is increasing globally. Around $80 \%$ of those infected are between 17 and 33 years old, with a peak age group of 20-24 years. In women, the lesions may be found on the vulva, in the vagina, and on the cervix [8], [9]. The incubation period is approximately $5-6$ months in women. Risk factors for infection include smoking, hormonal contraception, multiple sexual partners, and early age during sexual intercourse. CA lesions on the skin surface manifest as lobulated papules averaging 2-5 $\mathrm{mm}$ in size. Lesions are often multifocal and shaped like cauliflower with foul odor. The color of lesions is generally gray, pale, yellow, or pink [3], [10], [11]. The diagnosis of CA in this patient was based on history taking and physical examination. In cases of doubt, additional examinations can be carried out in the form of acetic acid test, colposcopy, histopathological examination, dermoscopy examination, and identification of the HPV genome [4]. Several treatment modalities of CA include topical therapy (imiquimod, podofilox, sinecatechins, and TCA), physical removal of the lesion with cryotherapy, electrocautery, laser, photodynamic therapy, or surgical excision. However, some of these therapeutic modalities can cause physical adverse events such as pain, itching, burning, and irritation [1].

The patient in this case was treated using topical betel leaf extract, a traditional herbal medicine found in Indonesia. Betel leaf (Piper betel L.) has anti-inflammatory, anti-bacterial, antioxidant, antidermatophyte, anti-proliferative, cytotoxic, and analgesic 
effects, as well as aiding wound healing process. The chemical components contained in betel leaf include piperol-A, piperol-B, and methyl piper betlol, piper betlol Betel leaf contains starch, sugar, diastase, and essential oils consisting of terpinen-4-ol, safrole, allyl pyrocatechol monoacetate, eugenol, eugenyl acetate, hydroxyl chavicol, eugenol, piper betol, and betel oil containing cadinene carvacrol, allyl catechol, chavicol, p-cymene, caryophyllene, chavibetol, cineole, and estragole as main components. Phytochemical analysis of betel leaf also showed the presence of alkaloids, tannins, carbohydrates, amino acids, and steroidal components. The main component in betel leaf is the volatile oil (essential oil) in the leaves of various countries, which is called Betel oil and contains 2 phenols, betel phenol (Chavibetol and Chavicol). Codeine has also been found in this betel leaf. Solvents such as ethanol, methanol, chloroform, n-hexane, ethyl acetate, dichloromethane, acetone, petroleum ether, benzene, and water are used for the extraction of betel leaf [12], [13], [14], [15].

Eugenol, one of the main components of betel leaf has been shown to have anti-inflammatory, anti-microbial, analgesic, antioxidant, anti-viral, and anti-cancer properties. Betel leaf also contains large amounts of antioxidants such as hydroxychavicol, eugenol, ascorbic acid, b-carotene, phenols, flavonoids, catechins, and isocatechins. Quercetin (part of the flavonoid) also has anti-viral, anti-bacterial, anti-carcinogenic and anti-inflammatory properties. Anticarcinogenic properties work through increasing apoptosis of mutated cells, inhibiting DNAsynthesis, inhibiting cancer cell growth, decreasing, and changing cellular signal transduction pathways. In several studies, it has been reported that betel leaf solvent also has antibacterial potential where methanol has a very strong potential followed by ethanol, chloroform, and ethyl acetate against many human pathogenic bacteria [13], [15], [16]. The patient experienced complete resolution of lesions after 4 weeks of therapy.

\section{Conclusion}

Office-made betel leaf extract therapy is a promising topical therapy for CA and is relatively simple to prepare. The plant has various mechanisms such as anti-proliferative and cytotoxic properties that can be studied further to prove its efficacy in the treatment of CA to prevent adverse events caused by other conventional destructive treatment modalities.

\section{References}

1. Bolan GA. Human papillomavirus infection. In: Rasmussen SA, Rutledge TF, Johnson DC, Wilson RJ, editors. Sexually
Transmitted Diseases Treatment Guidelines. United States: Department of Health and Human Services: Centers for Disease Control and Prevention; 2015. p. 84-90.

2. Hum M, Chow E, Schuurmans N, Dytoc M. Case of giant vulvar condyloma acuminata successfully treated with imiquimod $3.75 \%$ cream: A case report. SAGE Open Med Case Rep. 2018;6:2050313X18802143. https://doi. org/10.1177/2050313X18802143

PMid:30345054

3. Léonard B, Kridelka F, Delbecque K, Goffin F, Demoulin S, Doyen J, et al. A clinical and pathological overview of vulvar condyloma acuminatum, intraepithelial neoplasia, and squamous cell carcinoma. Biomed Res Int. 2014;2014:480573. https://doi.org/10.1155/2014/480573

PMid:24719870

4. O'Mahony C, Gomberg M, Skerlev M, Alraddadi A, de las Heras-Alonso M, Majewski S, et al. Position statement for the diagnosis and management of anogenital warts. J Eur Acad Dermatol Venereol. 2019;33(6):1006-19. https://doi.org/10.1111/ jdv. 15570

PMid:30968980

5. Serrano B, Brotons M, Bosch FX, Bruni L. Epidemiology and burden of HPV-related disease. Best Pract Res Clin Obstet Gynaecol. 2018;47:14-26. https://doi.org/10.1016/j. bpobgyn.2017.08.006

PMid:29037457

6. Yuan J, Ni G, Wang T, Mounsey K, Cavezza S, Pan X, et al Genital warts treatment: Beyond imiquimod. Hum Vaccin Immunother. 2018;14(7):1815-9. https://doi.org/10.1080/21645 515.2018.1445947

PMid:29505317

7. Hamka A, Fatimawali F, Datu OS, Tallei TE. Antibacterial activity of betel (Piper betle L.) fruit against Pseudomonas aeruginosa. Acta Biochim Indones. 2021;4(1):10.

8. Ugurlucan FG, Yasa C, Demir O, Dural O, Yavuz E, Akhan SE. Giant vulvar condylomata: Two cases and a review of the literature. Case Rep Obstet Gynecol. 2019;2019:1470105. https://doi.org/10.1155/2019/1470105

PMid:31223511

9. Leslie SW, Sajjad H, Kumar S. Genital Warts. Treasure Island, FL: StatPearls; 2021.

10. James WD. Viral diseases. In: Gabbedy R, Lowson K, editors. Diseases Andrews' of the Skin. $11^{\text {th }}$ ed. United States: Saunders, Elsevier; 2011. p. 401-4.

11. Sterling JC. Human papillomavirus infection. In: Kang $S$, Amagai $M$, Bruckner AL, Enk AH, Margolis DJ, editors. Fitzpatrick"s Dermatology. $9^{\text {th }}$ ed. United States: McGraw Hill Education; 2019. p. p. 3095-106.

12. Shah SK, Garg G, Jhade D, Patel N. Piper betle: Phytochemical, pharmacological and nutritional value in health management. Int J Pharm Sci Rev Res. 2016;38(2):181-9.

13. Madhumita M, Guha P, Nag A. Bio-actives of betel leaf (Piper betle L.): A comprehensive review on extraction, isolation, characterization, and biological activity. Phytother Res. 2020;34(10):2609-27. https://doi.org/10.1002/ptr.6715 PMid:32524688

14. Rekha V, Kollipara M, Gupta B, Bharath Y, Pulicherla KK A review on Piper betle L.: Nature's promising medicinal reservoir. Am J Ethnomed. 2014;1(5):276-89.

15. Jayalakshmi B, Raveesha K, Murali M, Amruthesh K. Phytochemical, antibacterial and antioxidant studies on leaf extracts of Piper betle L. Int J Pharm Pharm Sci. 2015;7(10):23-9.

16. Dwivedi V, Tripathi S. Review study on potential activity of Piper betle. J Pharmacogn Phytochem. 2014;3(4):93-8. 